\title{
The happy celiac: An oxymoron or a possibility?
}

\author{
Maurizio Esposito \\ Department of Human and Sport Sciences, University of Cassino, Cassino, Italy; m.esposito@unicas.it
}

Received 21 February 2012; revised 6 March 2012; accepted 20 March 2012

\begin{abstract}
Background: Several international studies, confirmed in Italy too, show a hard presence of socio-relational problems inside the celiac population. Methods: Qualitative study involving persons with celiac disease and their families. 25 individual semi-structured interviews were conducted in three Italian regions. Results: Problems of management of social life for celiac persons are experienced, specially in the fields of: school, work, travels and life outside the home. Conclusion: Chronic illness is a "biographical disruption" [1] and the whole society has to be invested to fight the burden of celiac persons in their possibility of access to public life.
\end{abstract}

Keywords: Celiac; Social; Quality of Life; Qualitative; Chronic Illness

\section{INTRODUCTION}

The relation between society and eating behaviors has long been demonstrated; in fact, the psychologist Gèrard Apfeldorfer asserts that the eating behavior is the cement of every human society [2]. Relations with others are often identified in the eating habits which may become part of the "transitional" element of connection but also, conversely, can become a "barrier" between in-group and out-group.

In some circumstances, this circuit stops, or goes through a moment of "anomic" suspension: these are conditions of chronic disease in which the life-food bond sometimes strongly affects the quality of life and access to social relations; this is certainly the case of celiac disease (CD), defined as permanent intolerance to gluten.

Eating is, as said, more than swallowing food in a physiological manner: it is a vehicle to correlate social and relational needs among people; a social, even political act, in some sense. Therefore, if a specific diet, such as the diet necessary for the celiac, limits the possibility of eating out, traveling and so on, it actually becomes a "burden" in terms of socialization, and, therefore, limits access to social opportunities.

\section{THE SOCIO-RELATIONAL EFFECTS OF CELIAC DISEASE. INTERNATIONAL RESEARCH DATA}

A few years ago [3], I asserted that the specificity of the chronically ill is that of a person who lives his life "inside" his disease, and considers his relationship with professional figures (doctors, nurses, therapists etc.) as one of the different moments of his existence; after all, his disease does not remain confined to the hospital only, but follows him home, to work or in his leisure activities, in all the relations he decides to have: it becomes his "existential background", a part that cannot be eliminated from his entire biography. Therefore, it becomes an existence, paradoxically, lived with continued effort of "normalization" because the main activity of the chronically ill is not only to stay alive or to keep his symptoms under control, but especially to live as normally as possible, despite his symptoms and illness [4]. The barrier that divides health and disease is thus a grey colored limen, which when surpassed forces the person to come to terms with his life, often making him reflect upon his own existence and the meaning of life itself.

Regarding our specific topic, a research conducted by Green et al. [5] confirms that gluten-free diet adherence for the celiac person is a significant social problem, demonstrating that one fourth of the subjects violate the diet when eating out and one fifth do not follow it at parties or social occasions. Another study conducted by Columbia University [6] analyzes the quality of life of people with CD in detail, describing the social, emotional and psycho-relational aspects: in a sample of 254 adults with CD, the researchers demonstrate that the social problems do not actually depend on the pathologyas is well known, it does not affect the physical and psychosocial status stricto sensu-but from following a strict diet; and, in fact, its negative impacts mainly occur when eating out (86\%), when traveling (82\%), in daily life at home (67\%), and in terms of job and career (41\%).

These data are supported by a study conducted by Karajeh and associates [7], showing that diet compliance is very difficult for people with $C D$, especially when eating away from home. In particular, this may depend on the lack of knowledge that staff preparing food in 
public places have about the problem: the authors confirm the fact that these people, paradoxically, often have less knowledge of the problem than the general population. This means that many people with CD show distrust when they have to eat out, and this causes significant restrictions on their social life and quality of life compared to people without this disorder (infra).

As with other chronic problems, it seems that the weakest population is the most affected in socio-relational terms. Adolescence is an emblematic age for diet compliance: Cinquetti et al. [8] demonstrate in a qualitative study how most celiac adolescents show feelings of anxiety, perception of being different and concern for their future life. Another qualitative study recently conducted by Swedish researchers with the use of the focus group technique [9] also indicates that non-adherence to diets is a common behavior, even for people aware of what it entails, and attempts to explain the possible causes: in particular, the findings show a significant selfperception of being different (related to lunch time), mainly due to the unattractive appearance of the food they have to eat and the scarce availability of gluten-free restaurants and snack bars. Moreover, even when such areas are accessible, the requests must always be accompanied by explanations, recommendations and discussions that make people with CD more "visible" than others who have not this disorder: this passage from a condition of invisibility to one of a forced visibility — which sometimes becomes a real public "display"-makes the person feel socially stigmatized, as the results of our empirical research illustrate (infra).

Consequently, in order to keep a coveted invisibility, sometimes teenagers prefer not to "stick" to their diet, concealing the problem so as to be accepted by their social group. A respondent's story to a Swedish study [10] about his adolescence can be indicative "there are a lot of horrible things concerning my time at school... at meal times... that was awful... I was always asking: can I eat this?... once when it was fish fingers... then she (the woman in the school-dining-hall) said... yes, of course you can. So I ate them and became really sick. It very often happened that I got the wrong food at school. I didn't dare to eat the food at school, brought my own lunch box. I get so very angry”. This can have significant negative conesquences on the person's social life: in fact, when domestic life produces less stress than social life, the individual prefers a sort of "withdrawal" from the public sphere resulting in possible consequent feelings of isolation and seclusion.

Moreover, women with CD seem to be more conditioned than men: In fact, Hallert's et al. survey [11] shows a great difference between men and women measured with the Protocol "Burden of Illness", which tests the perceived level of concern and restrictions on daily life: women are less satisfied after ten years of diet, especially for the CD impact which restricts socialization and public relations. The same authors, in a survey performed the following year [12] confirm the presence of a poorer quality of life for women, related mainly to three dimensions: self-perception of their body, social consequences of their illness and coping strategies with CD: specifically, women complain about a greater impact of this disease on their ability to socialize and participate in important moments of their lives. A recent study [13] also confirms these findings, showing a significant difference regarding the perceived quality of life measured with the "Psychological General Well-Being Index", between the male and female population, particularly with regards to feelings of general anxiety, depression and stress levels. More specifically, the mentioned research at Columbia University [6] shows that gender differences are highly significant in this context; in fact, eating out represents a problem for $65 \%$ of women (versus $20 \%$ of men), traveling for $64 \%$ of women (versus $18 \%$ of men), family life for $49 \%$ of women (versus $18 \%$ of men) and diet compliance, in terms of job and career, is a problem for $26 \%$ of women (versus $15 \%$ of men).

The impact that the presence of a person with CD has on the social life of other people living with him every day, beginning with the family members, should neither be overlooked. This disease affects the social life of these people, forcing them to a kind of unconscious "withdrawal". But that is not all: recent studies [14] specifically confirm that the presence of a celiac person within the family leads to a reorganization of social roles, especially with regards to women. In this sense, the new management becomes a task to be pursued collectively, a sort of "family caring" of the problem, according to what Anthony Giddens has called sense of "ontological security" [15]. Very few international studies on family members and partners of people with $\mathrm{CD}$ have been carried out; one conducted by Sverker et al. in Sweden [16] demonstrates how the presence of $\mathrm{CD}$ in the family leads to a reorganization of everyday life; in particular, families of people with CD experience great emotional stress due to continuous and generalized feelings of guilt, anxiety and vulnerability; one father told me: "A few days ago I was preparing breakfast for my children, it was early in the morning and I did it as usual. At one point, looking at the table, I realized that there were only gluten-free products, so I felt guilty for not having thought about Marco's two other brothers, who are not celiac, and who unconsciously I had forgotten...”

Moreover, the emotions described above regarding people with $\mathrm{CD}$ (that is, a sense of isolation, fear, shame and concern for bothering others) seem to extend to all the family members; at the time of diagnosis, the people close to the person with CD experience a sense of confu- 
sion, bewilderment about the possibilities of conducting a normal life, vulnerability, fatalism associated with resignation, and ultimately, powerlessness.

\section{CELIAC DISEASE AS A SOCIAL DISORDER. FIELD RESEARCH}

This paper presents the first results of a qualitative empirical research conducted in three Italian regions (Lazio, Campania, Emilia Romagna) on a sample of 25 subjects with CD, aged between 19 and 46. The contents of the semi-structured interviews focus primarily on the social and relational aspects of the people under study. The interviews were conducted in 2010 and 2011 by researchers of "Osservatorio di Ricerca Sociale Applicata Francesco Battisti”, University of Cassino, through snowball sampling, which allowed conducting interviews in an empathic way with a minimum possibility of errors and distortions. The instrument used, the semi-structured interview, proved to be an optimal technique to understand the respondents' subjective sense, minimizing the possibilities of miscommunication. We try to give importance to that part of interaction intended as a communicative relation in its multiple manifestations, allowing to describe events in their wholeness, with the primary purpose of understanding them; quality, in this sense, assumes the meaning of "an epistemology which interprets the world through many different characters, to successively recompose and integrate them” [17].

The main findings which emerge from the interviews are: fear, isolation, social withdrawal, organizational difficulties and disruption from the psycho-social life conducted before diagnosis.

These fragments of answers seem indicative:

"I felt a burden for my friends, when we went out I needed to know in advance where we were going to be able to organize myself" (male, 35 years old).

"So as not to feel a burden I used to invent excuses like, 'I can't come to the party tonight, I have a headache", (female, 40 years old).

Adherence to a gluten-free diet, as mentioned, has not obvious impacts only when eating, but on all the social life of people with CD. In fact:

"Seeing I can't eat some things makes me limit going out with my friends" (female, 21 years old).

"I prefer inviting friends at home so I can prepare food that is adapt for me. Eating out is sometimes very stressful" (female, 41 years old).

Our results are similar to the study performed by Sverker, Hensing and Hallert [18]. In an article emblematically entitled: "Controlled by food", a series of "dilemmas” experienced by people with CD related to meal times, job management, moments of shopping and traveling are explored. The main visible dilemmas experienced concern three topic aspects: emotions, social relations and coping with daily life.

In particular, the most recurrent emotions (measured with the use of the Critical Incident Technique Scale) are: a sense of isolation and loneliness, fear of eating contaminated food, shame for having to publicly admit a disorder not understood by the general population, concern of being a bother for others, and therefore not able to lead an acceptable social life. In particular, the sense of isolation is felt at parties, at social occasions and also at home, when it is impossible to share lunchtime and dinnertime with other family members; moreover, when on holiday with friends persons with CD have to pull out a rice wafer while others can eat fresh bread or freshly baked croissants. As one woman said to the researchers: "My husband and children had... they bought freshly baked bread and I'm sitting there with my dry crisp bread. That was a disappointment" [18]. A feeling of shame, as mentioned, limits the social life of people with $\mathrm{CD}$, the fear of being a bother appears when even a simple stroll in town can become a tragedy; another respondent in the Swedish survey says: "we had to go to three cafés before I could eat anything. I really felt that!” (Ibidem).

Furthermore, people with CD are terrified of eating something that can become poison for them, a fear becoming distrust towards people preparing food, having to ask at restaurant several times that there is no gluten in their dish, and when assured, ask to be reassured also on cross-contamination risks, thus appearing unfriendly, sometimes unpleasant, or even having to argue with the staff. This is present especially in our survey in the answers of persons of South Italy.

Some respondents told us:

"Before sitting at the table I must always speak to the chef in the kitchen to explain my problem and apologize for any inconvenience” (male, 27 years old).

"I often ask the waiter two or three times if he has understood that the rice for me has to be cooked in a particular pot, this makes me feel so unpleasant and antisocial" (male, 30 years old).

This does not only occur when eating out, but also within the family, where the presence of a relative or an elderly person who has not much knowledge about this disorder (therefore not paying particular attention to possible contamination risks) makes the person with CD significantly weaker.

Another emotion that is often present is the feeling of being a bother, fear of disturbing: and so, for instance, the celiac person avoids bringing food from the chemist's to public places, but simply prefers to order a harmless piece of meat or salad, so as not to give explanations.

The dilemmas investigated by Sverker, Hensing and Hallert linked to social relations are: excessive and un- 
wanted visibility, sense of abandonment and of being forgotten together with attempts of "avoiding" to reveal the problem. Specifically, excessive visibility of the problem occurs when the pathology becomes the principal subject of conversation with friends or at work. However, the main problem for a person with $\mathrm{CD}$ in this complex society certainly is fear of being avoided, forgotten, set aside, ultimately, excluded: this is the case of one Swedish respondent, who says: "at work they bought cream buns for everyone. But they forgot me. So everyone had cream buns except for me" [18]. Some of our respondents confirm these findings:

"So as not to explain that I am celiac I said I was not hungry and I stayed at home” (male, 45 years old).

"I often say that I am on a diet and eat only vegetables" (female, 43 years old).

"I sometimes make an exception to the diet so as not to justify myself" (female 22 years old).

"I often found myself away from home and I couldn't find anything to eat so I had to go back home" (male, 42 years old).

"When my plate arrives at the restaurant, I sadly see that everybody is looking at it, curious to see my food, they want to taste it, this really embarrasses me, I feel like I am sick" (female, 20 years old).

Furthermore, sometimes the celiac doesn't feel like publicly admitting having this disorder so as not to explain, motivate, speak up when he doesn't want to; and so he can miss the opportunity of going to that restaurant with friends because they can't serve you and you invent excuses like, "but no, you don't eat good food there", and many times you even eat food with gluten to avoid having to publicly admit that you are celiac. This choice, motivated by a legitimate desire of "belonging" to the group, however, soon proves illusory: in fact, profoundly analyzing, this behavior reveals that it does not keep you "together" but, on the contrary, accentuates the sense of isolation and, above all, the self-perception of being different.

Another aspect in which the dilemma often becomes insurmountable regards every day life, complicated by three principal factors: restricted choice of food, work overload and feeling constantly and perpetually "hanging in the balance" in regards to physical and social risks. Regarding the first aspect, tasty gluten-free food is not always easy to find, without considering that this food sometimes costs four times more than normal food, creating problems of unfairness and social inequality which effectively constitute a sort of health divide. The work overload does not only regard the celiac person but also his family and the people who are part of his daily life, who have to wash double the amount of plates, cook and bake bread twice as often, be careful when cleaning the tablecloths and therefore, perform tasks that are not physically tiring but cause a great mental stress overload. Finally, the perennial risk perception during the daily life of people with $\mathrm{CD}$, obliges them to be careful at all times, therefore renouncing to spontaneity and lightness even during evenings out with friends; in some cases, always being on a diet absorbs the person's whole life, reminding him constantly of being sick, in his individual perception (illness) and in the social representation of the disease (sickness). The answers to the interviews confirmed this furthermore:

"I went to a famous pizzeria in Naples with my friends that night and I brought my frozen pizza from home. When I went to the chef to have it heated up, all the customers looked at me with pity, how embarrassing!" (female, 24 years old).

"I have a recurring dream: to eat with my friends without fear of being sick” (female, 23 years old).

"I'm tired of seeing people look at me with compassion as if I'm dying” (male, 39 years old).

\section{DISCUSSION}

As discussed in many studies [19], the social aspects evidenced in CD are fundamental but, at the same time, often neglected by international research. Gluten free perennial diet adherence (to date, without possible alternatives), is undoubtedly a hard burden to cope with during the everyday life of the person with $\mathrm{CD}$ and those surrounding him. In some studies [20], the explicit element of social exclusion is specified, evidencing how the person with CD can often be described as a social outcast and outsider. In another research [18], people with CD say they feel like a burden when they are in company, a sort of social nuisance, especially during the dreadful lunchtime and dinnertime, and particularly when these moments are characterized as "social" stricto sensu.

The mother of a child with CD told: "We went to a pub to spend an evening out with friends. We had organized everything without planning and weren't able to explain that our child had CD. Fortunately, we had a gluten-free sandwich in our bag. When we arrived at the pub, we went to the kitchen to tell the chef to prepare a hamburger apart, but he did not want any responsibility. The hob was only one and could therefore contaminate his food. We had to leave, return home, but my son does not understand why... I wonder if this is not an emergency. It is outrageous that my son cannot have a life like his other friends!"

The burden for people with $\mathrm{CD}$ starts from their childhood, when with their little brothers they watch a TV advertisement showing families happily sitting at the table eating snacks which seem to sweeten their lives and solve their problems. It is in these moments that children ask for these snacks but they are given others, from a 
chemist's, and when the child sees his own food on the shelf among medicine at the chemist's, he imagines being a social outcast and asks, perhaps quietly, the question parents never wanted to hear: "But am I different?".

Therefore, some parts of the day can become real nightmares: this is the case of breakfast time at the hotel, where often the only thing available, if you do not tell them about your disorder first, is yogurt; or at the dinner party organized by friends without prior notice, so that if you don't bring your pre-cooked pizza from home (or that night you do not feel like eating it) you have to order a steak when others eat a sandwich or pizza, and you get ready for that inevitable remark, that will certainly arrive, from that uneducated friend: "here you are, always different, why don't you eat a pizza, like us?”; or still, those evenings at parties or special occasions, where you arrive having already eaten, so as to avoid having to expose yourself; and those trips, always accompanied by an extra suitcase for that food you could not find there; and on Sundays in church, just that Sunday, when you wanted to take your communion, but you did not remember to bring your "special host".

Children, as mentioned before, are the ones who suffer most this social stigma: they are the ones who must renounce to eat what their friends eat during their school break or at a birthday party; they are the ones who have to bring their "special" tray at social occasions; they are the ones who cannot help but wonder why, not having any symptoms nor pain, they should be treated differently. Little Matteo's story can be indicative: one day, his teacher, even though aware of the child's problem, brought a birthday cake to celebrate her birthday and, when she offered Matteo a slice, he answered: "sorry teacher, but I cannot eat it, it will give me stomachache!”, or another story an eight year old child's mother told us: "we were at a birthday party and my son was the only child with CD, so I asked if we could put his special cake next to the birthday cake so he wouldn't feel different, but the mother replied that this would ruin the pictures of the cutting of her son's birthday cake. I felt a mixture of shame and anger". Another story reported by Corposanto [21] confirms this furthermore: "The inconveniences associated with CD disease are many, especially when away from home: we have to organize meals carefully and see that nothing is missing especially now that he is young and the psychological aspect is important so that he doesn't feel different and marginalized... the difficulty will be to tell our son, as all children with CD, that this is a life-long intolerance! He often asks if he will be able to eat normal snacks when he turns ten" (My translation).

\section{CONCLUSIONS}

From the international surveys considered and from the empirical data of our survey, we can therefore see, without any doubt, that for people with CD even images of food change their social semantics: if food, before diagnosis, represented a moment of pleasure and an opportunity to be together (togetherness), after it represents "disintegration" and becomes a vehicle for diversity, like in the case of holidays, which should be a moment of rest and refreshment:

"We go on holidays alone, so we can organize ourselves freely, especially with meals, without bothering anybody" (male, 46 years old).

"I have often renounced going on holiday for long, or too far, because I did not know how to organize myself" (male, 30 years old).

From the research data, it is evident that people who live this condition essentially decide to live "day by day", redefining not only their experiential mode of existence in society, but also try to reorganize their own life after the eruption of the disease, which constitutes a moment of crisis as Michael Bury well represents with the concept of "biographical disruption" [1].

Experiences of psycho-social support for people with $\mathrm{CD}$ and their families have been performed internationally. The assumption is that the socio-psychological and relational difficulties that these people are forced to undergo, as demonstrated in many contexts, can lead to diet non-adherence, which, in turn, causes great damages.

From a sociological analysis perspective that should become social action, it should be important to operate on three closely related arenas: a purely scientific-informative campaign, exploring more in depth conditions of the disease and its socio-relational course, through survey methodologies that favor qualitative analysis, such as, for example, the illness narratives of people with $C D$, which allow to study a phenomenon not yet well understood in terms of its impact and social awareness.

Another level of intervention should be identified in the macro sense, like increasing public awareness on this disorder, and therefore favoring allocation and distribution of ad hoc products in all retail chains, from the big complex chain to the smallest, to vending machines for snacks - starting from public places-of gluten-free products; possibly more than one type, to make the person with $\mathrm{CD}$ able to choose and not settle for what he can only find, in a society (real and not utopian) which should become more and more celiac-friendly. A lot has been said-legitimately_about removing architectural barriers that prevent disabled people access to many places; indeed, the same should happen for people with $\mathrm{CD}$, who constantly live in a state of apprehension, concern and worry ("to be on call"), therefore limiting and conditioning socialization opportunities.

To conclude, at a micro level, great effort should be made to improve and implement support, not only for the person with CD but for all the social environment sur- 
rounding him, and in particular, for his family members so as to avoid the psychological and relational long term complications that diet adherence may cause. Since the course of the disease is divided into two phases, a crisis at the time of diagnosis (as a disruption of normal routine) and the management phase which is lifelong [22], intervention programs should be tailored for each single person, considering that every person is unique and unequalled.

\section{REFERENCES}

[1] Bury, M.R. (1982) Chronic illness as biographical disrupttion. Sociology of Health and Illness, 4, 167-182. doi:10.1111/1467-9566.ep11339939

[2] Apfeldorfer, G. (1995) Mangio dunque sono: Obesità e anomalie del comportamento alimentare. Marsilio, Venezia.

[3] Esposito, M. (2008) Introduzione. In: Battisti, F.M. and Esposito, M. Eds., Cronicità e dimensioni socio-relazionali. Salute e Società, FrancoAngeli, Milano.

[4] Strauss, A., et al. (1975) Chronic illness and quality of life. Mosby, St. Louis.

[5] Green, P.H.R., et al. (2001) Characteristics of adult celiac disease in the USA results of a national survey. American Journal of Gastroenterology, 96, 126-131.

[6] Lee, A. and Newman, J.M. (2003) Celiac diet: Its impact on quality of life. Journal of the American Dietetic Association, 103, 1533-1535. doi:10.1016/j.jada.2003.08.027

[7] Karajeh, M.A., et al. (2004) Are patients with celiac disease socially restricted by a gluten free diet? Gut, 53, pp. 4-5.

[8] Cinquetti, et al. (1997) L'adolescente e la malattia celiaca. Pediatria Medica e Chirurgica, 19, pp. 397-399.

[9] Olsson, C., et al. (2009) Food that makes you different. The stigma experienced by adolescents with celiac disease. Qualitative Health Research, 19, 976-984. doi:10.1177/1049732309338722

[10] Sverker, A., Hensing, G. and Hallert, C. (2005) "Controlled by food": Lived experiences of celiac disease. Journal of Human Nutrition and Dietetics, 18, 171-180.

\section{doi:10.1111/j.1365-277X.2005.00591.X}

[11] Hallert, C., et al. (2002) Living with celiac disease: Controlled study of the burden of illness. Scandinavian Journal of Gastroenterology, 37, 39-42. doi:10.1080/003655202753387338

[12] Hallert, C., et al. (2003) Perceptions of health-related quality of life of men and women living with celiac disease. Scandinavian Journal of Caring Sciences, 17, 301307. doi:10.1046/j.1471-6712.2003.00228.x

[13] Roos, S., et al. (2006) Psychosocial well-being of adult coeliac patients treated for ten years. Digestive and Liver Disease, 38, 177-180. doi:10.1016/j.dld.2006.01.004

[14] Gregory, S. (2005) Living with chronic illness in the family setting. Sociology of Health and Illness, 27, 372-392. doi:10.1111/j.1467-9566.2005.00447.x

[15] Giddens, A. (1991) Modernity and self-identity. Self and society in the late modern age. Polity, Cambridge.

[16] Sverker, A., et al. (2007) Sharing life with a gluten-intolerant person: the perspective of close relatives. Journal of Human Nutrition and Dietetics, 20, 412-422. doi:10.1111/j.1365-277X.2007.00815.X

[17] Cipolla, C. (1997) Epistemologia della tolleranza. FrancoAngeli, Milano.

[18] Sverker, A., et al. (2009) 'I lose all these hours...' Exploring gender and consequences of dilemmas experienced in everyday life with celiac disease. Scandinavian Journal of Caring Science, 23, 342-352. doi:10.1111/j.1471-6712.2008.00628.x

[19] Fasano, A. (2005) Clinical presentation of celiac disease in paediatric population. Gastroenterology, 128, 68-73. doi:10.1053/j.gastro.2005.02.015

[20] Hallert, C., et al. (1998) Quality of life of adult celiac patients treated for ten years. Scandinavian Journal of Gastroenterology, 33, 933-938.

[21] Corposanto, C. (2008) Celiachia e capitale sociale. Uno sguardo sociologico sulle intolleranze alimentari. In: Battisti, F.M. and Esposito, M. Eds., Cronicità e dimensioni socio- relazionali. Salute e Società, Anno.

[22] Bolano, M.A. and Martin, A.A. (1996) La prevencion como estrategia de abordaje en una enfermedad cronica: La enfermedad celiaca. Pediatrika, 16, 33-37. 